\title{
A Comparative Study of the Hemoglobin-Maintaining Effects Between Epoetin- $\beta$ Pegol and Darbepoetin- $\alpha$ in Patients with Chronic Kidney Disease During 3 Months Before Dialysis Initiation
}

\author{
Satoru Oka ${ }^{1,2} \cdot$ Yoko Obata $^{1,2,3} \cdot$ Kenta Torigoe $^{1,2} \cdot$ Miki Torigoe $^{1,2}$. \\ Shinichi Abe ${ }^{1,2} \cdot$ Kumiko Muta $^{1}$ Yuki Ota ${ }^{1,2} \cdot$ Mineaki Kitamura $^{1,4}$. \\ Satoko Kawasaki $^{1}$ Misaki Hirose ${ }^{1}$ - Tadashi Uramatsu ${ }^{1} \cdot$ Hiroshi Yamashita $^{5}$. \\ Hideyuki Arai ${ }^{6} \cdot$ Hiroshi Mukae $^{2}$ Tomoya Nishino ${ }^{1,2}$
}

Published online: 25 May 2017

(C) The Author(s) 2017. This article is an open access publication

\begin{abstract}
Background and Objective We compared the hemoglobinmaintaining effects between continuous erythropoietin receptor activator (CERA) and darbepoetin- $\alpha$ (DA) in patients with chronic kidney disease (CKD) during the 3 months before dialysis initiation.

Methods This study was conducted with 37 CERA-administered patients and 26 DA-administered patients who had initiated dialysis at a participating facility between January 2012 and December 2014. We investigated clinical laboratory data 3 months before and at dialysis initiation, and compared these data between the CERA and DA groups.
\end{abstract}

Yoko Obata

yobata@nagasaki-u.ac.jp

1 Department of Nephrology, Nagasaki University Hospital, 1-7-1 Sakamoto, Nagasaki, Nagasaki 852-8501, Japan

2 Department of Respiratory Medicine, Nagasaki University Graduate School of Biomedical Sciences, 1-7-1 Sakamoto, Nagasaki, Nagasaki 852-8501, Japan

3 Medical Educational Development Center, Nagasaki University Hospital, 1-7-1 Sakamoto, Nagasaki, Nagasaki 852-8501, Japan

4 Department of Blood Purification, Nagasaki University Hospital, 1-7-1 Sakamoto, Nagasaki, Nagasaki 852-8501, Japan

5 Department of Nephrology, National Hospital Organization Nagasaki Medical Center, 2-1001-1 Kubara, Omura, Nagasaki 856-8562, Japan

6 Department of Nephrology, Japan Community Health Care Organization Isahaya General Hospital, 24-1 Eishouhigashimachi, Isahaya, Nagasaki 854-8501, Japan
Results No significant differences in hemoglobin level or reticulocyte count were found between the two groups 3 months before dialysis initiation. However, at dialysis initiation, the hemoglobin level (CERA $9.82 \pm 1.52$ vs. DA $8.79 \pm 1.07 \mathrm{~g} / \mathrm{dL} ; P=0.003)$ and the reticulocyte count (CERA $5.21 \pm 2.95$ vs. DA $3.15 \pm 1.62 \times 10^{4} / \mu \mathrm{L}$; $P=0.004)$ were significantly higher in the CERA group than in the DA group. Moreover, the extent of changes in the erythropoietin resistance index during the 3 months before dialysis initiation was significantly increased in the DA group compared with the CERA group.

Conclusions Our results suggest that CERA may be more effective than DA in maintaining hemoglobin levels in patients with CKD during 3 months before dialysis initiation.

\section{Key Points}

During 3 months before dialysis initiation, the hemoglobin level was maintained in the continuous erythropoietin receptor activator (CERA) group and decreased in the darbepoetin- $\alpha$ (DA) group.

The reticulocyte count was higher in the CERA group than in the DA group during 3 months before dialysis initiation.

The extent of changes in the erythropoietin resistance index in the 3 months prior to dialysis initiation was less in the CERA group than in the DA group. 


\section{Introduction}

Renal anemia is a known risk factor for development of cardiovascular events in patients with chronic kidney disease (CKD); in addition, renal anemia itself also contributes to the progression of CKD [1, 2]. Further, it has been proposed that patients with CKD at the pre-dialysis stage may develop cardiorenal anemia syndrome, in which heart disease, renal disease, and anemia influence each other [3,4]. Since the commercialization of recombinant human erythropoietin (rHuEPO), an erythropoiesis-stimulating agent (ESA) designed to treat renal anemia, it has been used to treat renal anemia in patients with CKD at the pre-dialysis stage. rHuEPO improves patients' symptoms of chronic anemia and quality of life and may also help inhibit the decrease in renal function and ameliorate cardiac hypertrophy [2, 5-9]. Therefore, ESA use is recommended for the treatment of renal anemia in patients with CKD at the pre-dialysis stage.

However, using conventional rHuEPO to manage renal anemia during the pre-dialysis period, especially just prior to dialysis initiation, is difficult because its dosage is limited and its half-life is short (epoetin- $\alpha$ : $6.8 \mathrm{~h}$ when administered intravenously and $19.4 \mathrm{~h}$ when administered subcutaneously; epoetin- $\beta$ : $8.8 \mathrm{~h}$ when administered intravenously and $24.2 \mathrm{~h}$ when administered subcutaneously [10]). In the Co-JET study, the hemoglobin level decreased to $8.35 \mathrm{~g} / \mathrm{dL}$ at dialysis initiation despite rHuEPO treatment [11]. The long-acting ESA darbepoetin$\alpha$ (DA) and epoetin- $\beta$ pegol, also known as continuous erythropoietin receptor activator (CERA), have recently been commercialized. Since these are expected to have an improvement effect on anemia without significantly increasing the dosage and frequency of administration compared with rHuEPO, these are now the mainstream treatments for renal anemia in non-dialysis CKD patients. Although there have been several studies on the efficacy of ESAs in the pre-dialysis stage [12, 13], they have only shown the difference in the hemoglobin level and did not mention the extent of changes in transferrin saturation (TSAT), ferritin, or reticulocyte count. In the present study, we focused on the efficacy of ESAs during 3 months before dialysis initiation and we directly compared not only the hemoglobin-maintaining effects but also reticulocyte count and iron metabolism between CERA and DA in patients with CKD during this period.

\section{Methods}

\subsection{Participants}

Participants were selected from 97 patients with CKD at the pre-dialysis stage who had been receiving outpatient care and initiated dialysis at the facilities participating in this study between January 2012 and December 2014. Patients who met the selection criteria outlined below were selected and divided into CERA (37 participants) and DA (26 participants) groups. CERA and DA were administered according to the approved dosage and administration interval in Japan. In addition, all participants in the present study were injected with ESA subcutaneously. The administration interval of ESA in most of participants was once every 4 weeks and there was no significant difference in the administration frequency between the CERA and DA groups. The criteria of the frequency and dosage of CERA and DA were decided by the attending physician, taking the clinical situation into consideration. Based on the 2008 Japanese Society for Dialysis Therapy: Guidelines for Renal Anemia in Chronic Kidney Disease [14], the target hemoglobin level range was from 11.0 to $13.0 \mathrm{~g} / \mathrm{dL}$, and iron was administered to patients with TSAT $\leq 20 \%$ and ferritin $\leq 100 \mathrm{ng} / \mathrm{mL}$. Iron was generally given by oral administration.

Selection criteria were as follows: (1) patients who received ESA therapy for at least 3 months before dialysis initiation; (2) patients who had received the same ESA treatment for a period of 6 months before dialysis initiation (or from the initiation of ESA therapy until the dialysis initiation if the patient had been treated with ESA for 3-5 months before dialysis initiation); (3) patients whose blood test results were available from 3 months before dialysis initiation, and who had blood tested on the day of ESA administration; and (4) patients who had not received an erythrocyte transfusion during the 3 months before dialysis initiation. Figure 1 shows an overview of the patient selection.

This study was not supported by any industry funding. This study followed the Declaration of Helsinki and the Ethical Guidelines for Medical and Health Research Involving Human Subjects. This study was approved by Nagasaki University Hospital's ethical review board (Approval Number 15122111).

\subsection{Methods}

The following data were collected 3 months before and at dialysis initiation, and a comparative study between the CERA and DA groups was carried out.

- Patient characteristics: age, sex, primary diseases that caused the end-stage renal disease (ESRD), co-morbidities, causes for initiating dialysis, timing of ESA initiation, ESA dosage, erythropoietin resistance index [ERI $(\mu \mathrm{g} / \mathrm{kg}$ per $\mathrm{g} / \mathrm{dL}$ every 4 weeks $)=$ ESA dosage per 4 weeks/(weight $\times$ hemoglobin level)], percentage 


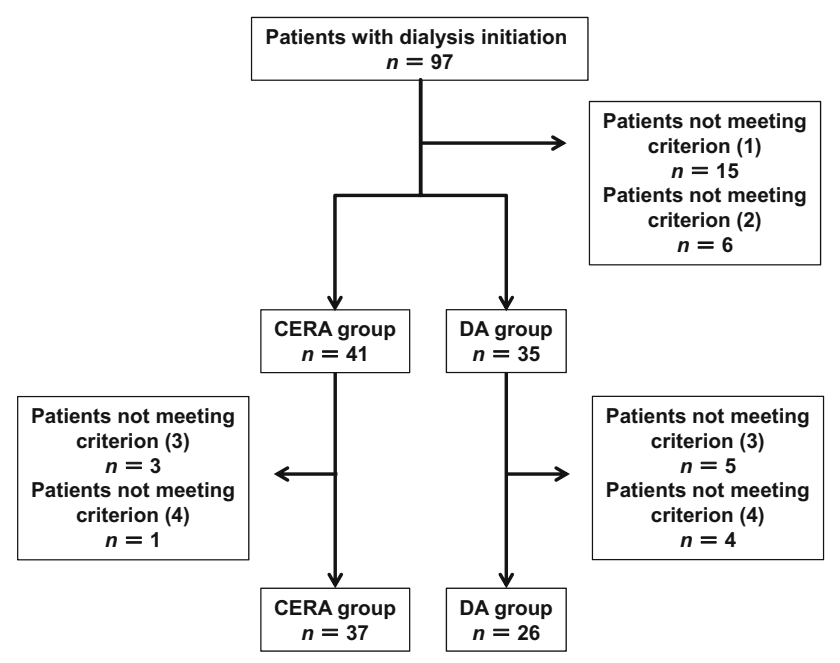

Fig. 1 Flowchart showing the selection of patients for this study. Selection criteria: (1) patients who received ESA therapy for at least 3 months before dialysis initiation; (2) patients who had received the same ESA treatment for a period of 6 months before dialysis initiation (or from the initiation of ESA therapy until the dialysis initiation if the patient had been treated with ESA for 3-5 months before dialysis initiation); (3) patients whose blood test results were available for 3 months before dialysis initiation, and who had blood tested on the day of ESA administration; and (4) patients who had not received an erythrocyte transfusion in the 3 months before dialysis initiation. CERA continuous erythropoietin receptor activator, $D A$ darbepoetin- $\alpha, E S A$ erythropoiesis-stimulating agent

of patients with hemoglobin $\geq 10 \mathrm{~g} / \mathrm{dL}$, and cardiothoracic ratio (CTR).

- Blood tests: hemoglobin level, mean corpuscular volume, reticulocyte count, albumin, blood urea nitrogen, creatinine, TSAT, ferritin, C-reactive protein, and estimated glomerular filtration rate (eGFR).

In addition, the two groups were compared with respect to the extent of changes in hemoglobin level, ESA dosage, ERI, TSAT level, ferritin level, eGFR, and the CTR during 3 months before dialysis initiation.

\subsection{Statistical Analysis}

Nominal variables were compared using Pearson's Chi square test or Fischer's exact test. Continuous variables of patient characteristics at dialysis initiation were compared using the Wilcoxon rank sum test. Continuous variables 3 months before dialysis initiation and at dialysis initiation were compared using one-way repeated-measure analysis of variance. Changes of continuous variables during 3 months before dialysis initiation were compared using analysis of covariance. Patient data are displayed as mean values \pm standard deviation. All statistical analyses were carried out using JMP ${ }^{\circledR}$ version 11 software (SAS Institute Inc., Cary, NC, USA), and a $P$ value $<0.05$ was considered to be statistically significant.

\section{Results}

\subsection{Patient Characteristics}

Patient characteristics are shown in Table 1. This study included some patients with co-morbidities, such as malignancies, chronic inflammatory diseases, and infections, which were likely to have caused anemia during the observation period; however, no significant difference in these factors was found between the two groups. Neither group included patients with co-morbid hematological disorders or gastrointestinal bleeding or who underwent surgery during the observation period. Among the patient characteristics at dialysis initiation, no significant difference was found between the groups in terms of age, sex, primary diseases of ESRD, percentage of co-morbidities, causes of initiating dialysis, timing of ESA initiation, or number of ESA administrations during the 3 months before dialysis initiation. There were no differences in the blood test values 3 months before dialysis initiation (Table 2). No significant difference was found between the groups in terms of the ESA dosage, ERI, percentage of patients with hemoglobin $\geq 10 \mathrm{~g} / \mathrm{dL}$, CTR, or percentage of patients receiving iron administration.

\subsection{Outcomes}

Clinical data collected at dialysis initiation are shown in Table 3. The changes in red blood cell (RBC) count, hemoglobin level (Fig. 2a), and reticulocyte count (Fig. 2b) during the 3 months before dialysis initiation were as follows: in the CERA group, the RBC count changed from $3.36 \pm 0.50$ to $3.32 \pm 0.50 \times 10^{6} / \mu \mathrm{L}$, hemoglobin level changed from $9.85 \pm 1.21$ to $9.82 \pm 1.52 \mathrm{~g} / \mathrm{dL}$, and reticulocyte count changed from $3.40 \pm 2.12$ to $5.21 \pm 2.95 \times 10^{4} / \mu \mathrm{L}$, whereas in the DA group, the RBC count changed from $3.24 \pm 0.28$ to $2.91 \pm 0.36 \times 10^{6} / \mu \mathrm{L}$, hemoglobin level changed from $9.84 \pm 0.71$ to $8.79 \pm 1.07 \mathrm{~g} / \mathrm{dL}$, and reticulocyte count changed from $2.12 \pm 1.03$ to $3.15 \pm 1.62 \times 10^{4} / \mu \mathrm{L}$. When dialysis started, the RBC count $(P=0.0003)$, hemoglobin level $(P=0.003)$, and reticulocyte count $(P=0.004)$ were significantly higher in the CERA group than in the DA group. The changes in ESA dosage (Fig. 3a) and in the ERI (Fig. 3b) were as follows: in the CERA group, the ESA dosage changed from $73.81 \pm 52.25$ to $92.87 \pm 63.29 \mu \mathrm{g} / 4$ weeks and the ERI changed from $0.154 \pm 0.119$ to $0.171 \pm 0.130 \mu \mathrm{g} / \mathrm{kg} / \mathrm{g} /$ $\mathrm{dL} / 4$ weeks, whereas in the DA group, the ESA dosage changed from $70.58 \pm 44.81$ to $109.15 \pm 61.94 \mu \mathrm{g} /$ 4 weeks and the ERI changed from $0.132 \pm 0.099$ to $0.200 \pm 0.119 \mu \mathrm{g} / \mathrm{kg} / \mathrm{g} / \mathrm{dL} / 4$ weeks. In both groups, the 
Table 1 Patient characteristics at dialysis initiation

\begin{tabular}{|c|c|c|c|}
\hline Characteristic & $\begin{array}{l}\text { CERA } \\
(n=37)\end{array}$ & $\begin{array}{l}\mathrm{DA} \\
(n=26)\end{array}$ & $P$ value \\
\hline Age (years) & $67.9 \pm 13.4$ & $67.8 \pm 13.5$ & 0.95 \\
\hline Sex (male:female) & $21: 16$ & $17: 9$ & 0.49 \\
\hline $\begin{array}{l}\text { Primary diseases of ESRD } \\
(\%)\end{array}$ & & & 0.12 \\
\hline Diabetic nephropathy & 43.3 & 34.6 & \\
\hline Chronic glomerulonephritis & 5.4 & 26.9 & \\
\hline Renal sclerosis & 32.4 & 26.9 & \\
\hline Others & 18.9 & 11.6 & \\
\hline \multicolumn{4}{|l|}{ Co-morbidities (\%) } \\
\hline Malignancies & 10.8 & 7.7 & 0.99 \\
\hline Infections & 5.4 & 3.8 & 0.99 \\
\hline $\begin{array}{l}\text { Chronic inflammatory } \\
\text { diseases }\end{array}$ & 5.4 & 0 & 0.51 \\
\hline $\begin{array}{l}\text { Causes of initiating dialysis } \\
(\%)\end{array}$ & & & 0.93 \\
\hline Volume overload & 20.6 & 23.1 & \\
\hline Uremia & 29.4 & 34.6 & \\
\hline Decline of eGFR & 38.2 & 34.6 & \\
\hline Others & 11.8 & 7.7 & \\
\hline Timing of ESA initiation (\%) & & & 0.46 \\
\hline $\begin{array}{l}\geq 6 \text { months before dialysis } \\
\text { initiation }\end{array}$ & 73.0 & 84.6 & \\
\hline $\begin{array}{l}5 \text { months before dialysis } \\
\text { initiation }\end{array}$ & 10.8 & 11.5 & \\
\hline $\begin{array}{l}4 \text { months before dialysis } \\
\text { initiation }\end{array}$ & 10.8 & 3.9 & \\
\hline $\begin{array}{l}3 \text { months before dialysis } \\
\text { initiation }\end{array}$ & 5.4 & 0 & \\
\hline $\begin{array}{l}\text { Number of ESA } \\
\text { administrations during } \\
3 \text { months before dialysis } \\
\text { initiation (times) }\end{array}$ & $3.6 \pm 1.1$ & $3.8 \pm 1.2$ & 0.41 \\
\hline
\end{tabular}

Values are given as mean \pm standard deviation for continuous variables and frequency $(\%)$ for nominal variables

CERA continuous erythropoietin receptor activator, $D A$ darbepoetin$\alpha, e G F R$ estimated glomerular filtration rate, ESA erythropoiesisstimulating agent, ESRD end-stage renal disease

ESA dosage increased as the time of dialysis initiation approached. In the CERA group, the ERI was successfully maintained until 1 month before dialysis initiation, whereas the ERI tended to increase in the DA group as the time of dialysis initiation approached. When dialysis started, no significant difference was found between the two groups in terms of the ESA dosage or ERI. When dialysis started, $47.4 \%$ in the CERA group and $19.2 \%$ in the DA group had hemoglobin $\geq 10 \mathrm{~g} / \mathrm{dL}$, and this difference was significant. Other laboratory values did not differ between the two groups.

Table 4 shows the changes in clinical data during 3 months before dialysis initiation. During this time, the extent of changes in the hemoglobin level $(P=0.006)$ decreased significantly more in the DA group than in the CERA group, whereas the extent of changes in ERI $(P=0.045)$ increased significantly more in the DA group than in the CERA group. The other data did not differ between the two groups.

\section{Discussion}

In this study, the RBC count, hemoglobin level, and reticulocyte count at dialysis initiation, as well as the percentage of patients with hemoglobin $\geq 10 \mathrm{~g} / \mathrm{dL}$, were significantly higher in the CERA group than in the DA group. In addition, the extent of changes in hemoglobin level decreased significantly more in the DA group, and the extent of changes in ERI increased significantly more in the DA group than in the CERA group. Based on those results, the hemoglobin level was maintained and the increase in ERI was suppressed more in the CERA group than in the DA group during 3 months before dialysis initiation. These differences between CERA and DA groups might be caused by several mechanisms: (1) the stronger erythropoietic effect of CERA just before dialysis initiation; (2) the increased efficiency of iron utilization due to the inhibitory effect of CERA on hepcidin; and (3) the inhibitory effect of CERA on its degradation by PEGylation.

First, this study included a comparison of reticulocyte count to examine the erythropoietic effect of each ESA and showed that, starting at 1 month before dialysis initiation, the reticulocyte count was significantly higher in the CERA group than in the DA group. These findings indicated that, even just before dialysis initiation, erythropoiesis was significantly more active in the CERA group than in the DA group. The erythropoietic effect shown in our study also suggests that CERA might be more beneficial than DA in the management of anemia just before dialysis initiation. However, the hemoglobin level was not increased, although there was a time-dependent increase in the reticulocyte count in the CERA group. We consider the involvement of shortened erythrocytes survival due to an increase of uremic toxins as a possible explanation for this finding. Generally, erythrocytes are degraded by serum sialidase and sequestered in the liver and spleen [15]. Moreover, it has been reported that serum sialidase activity is elevated and degradation of erythrocytes is more enhanced in patients with renal failure as the time of dialysis initiation approaches $[15,16]$. Thus, the degradation of erythrocytes might exceed their production as renal function declines, and the hemoglobin level was not increased despite an increased reticulocyte count in the CERA group.

Next, the percentage of iron administration and patients with low ferritin and low TSAT, which were the criterion 
Table 2 Clinical data 3 months before dialysis initiation

\begin{tabular}{llll}
\hline Clinical data & CERA $(n=37)$ & DA $(n=26)$ & $P$ value \\
\hline RBC count $\left(\times 10^{6} / \mu \mathrm{L}\right)$ & $3.36 \pm 0.50$ & $3.24 \pm 0.28$ & 0.27 \\
Hb level $(\mathrm{g} / \mathrm{dL})$ & $9.85 \pm 1.21$ & $9.84 \pm 0.71$ & 0.96 \\
MCV $(\mathrm{fL})$ & $90.12 \pm 5.90$ & $91.92 \pm 4.62$ & 0.23 \\
Ret count $\left(\times 10^{4} / \mu \mathrm{L}\right)$ & $3.40 \pm 2.12$ & $2.12 \pm 1.03$ & 0.09 \\
Alb $(\mathrm{g} / \mathrm{dL})$ & $3.55 \pm 0.61$ & $3.60 \pm 0.53$ & 0.76 \\
BUN $(\mathrm{mg} / \mathrm{dL})$ & $73.88 \pm 16.64$ & $72.81 \pm 19.57$ & 0.86 \\
$\mathrm{Cr}(\mathrm{mg} / \mathrm{dL})$ & $5.31 \pm 1.25$ & $5.92 \pm 2.00$ & 0.30 \\
TSAT $(\%)$ & $28.63 \pm 11.25$ & $35.27 \pm 11.75$ & 0.11 \\
Ferritin $(\mathrm{ng} / \mathrm{mL})$ & $165.32 \pm 140.42$ & $190.16 \pm 103.34$ & 0.52 \\
Patients with low TSAT $(\leq 20 \%)$ and low ferritin & 8.3 & 0 & 0.50 \\
$(\leq 100 \mathrm{ng} / \mathrm{mL})(\%)$ & & & \\
CRP $(\mathrm{mg} / \mathrm{dL})$ & $0.49 \pm 0.73$ & $0.27 \pm 0.28$ & 0.74 \\
eGFR $\left(\mathrm{mL} / \mathrm{min} / 1.73 \mathrm{~m}^{2}\right)$ & $8.86 \pm 2.64$ & $8.35 \pm 2.96$ & 0.47 \\
ESA dosage $(\mu \mathrm{g} / 4$ weeks) & $73.81 \pm 52.25$ & $70.58 \pm 44.81$ & 0.81 \\
ERI $(\mu \mathrm{g} / \mathrm{kg} / \mathrm{g} / \mathrm{dL} / 4$ weeks) & $0.154 \pm 0.119$ & $0.132 \pm 0.099$ & 0.50 \\
CTR $(\%)$ & $50.35 \pm 4.55$ & $49.34 \pm 7.46$ & 0.57 \\
Iron administration $(\%)$ & 29.7 & 11.5 & 0.13 \\
Patients with Hb $\geq 10 \mathrm{~g} / \mathrm{dL}(\%)$ & 48.6 & 42.3 & 0.62 \\
\hline
\end{tabular}

Values are given as mean \pm standard deviation for continuous variables and frequency (\%) for nominal variables

$A l b$ albumin, $B U N$ blood urea nitrogen, $C E R A$ continuous erythropoietin receptor activator, $C r$ creatinine, $C R P$ C-reactive protein, $C T R$ cardiothoracic ratio, $D A$ darbepoetin- $\alpha, e G F R$ estimated glomerular filtration rate, $E R I$ erythropoietin resistance index, $E S A$ erythropoiesis-stimulating agent, $H b$ hemoglobin, $M C V$ mean corpuscular volume, $R B C$ red blood cell, Ret reticulocyte, TSAT transferrin saturation

\begin{tabular}{llll}
\hline Clinical data & CERA $(n=37)$ & DA $(n=26)$ & $P$ value \\
\hline RBC count $\left(\times 10^{6} / \mu \mathrm{L}\right)$ & $3.32 \pm 0.50$ & $2.91 \pm 0.36$ & 0.0003 \\
Hb level $(\mathrm{g} / \mathrm{dL})$ & $9.82 \pm 1.52$ & $8.79 \pm 1.07$ & 0.003 \\
$\mathrm{MCV}(\mathrm{fL})$ & $89.93 \pm 7.03$ & $91.34 \pm 4.92$ & 0.24 \\
Ret count $\left(\times 10^{4} / \mu \mathrm{L}\right)$ & $5.21 \pm 2.95$ & $3.15 \pm 1.62$ & 0.004 \\
Alb $(\mathrm{g} / \mathrm{dL})$ & $3.34 \pm 0.67$ & $3.38 \pm 0.61$ & 0.80 \\
$\mathrm{BUN}(\mathrm{mg} / \mathrm{dL})$ & $88.78 \pm 30.74$ & $90.04 \pm 19.51$ & 0.83 \\
$\mathrm{Cr}(\mathrm{mg} / \mathrm{dL})$ & $7.71 \pm 2.38$ & $8.75 \pm 3.25$ & 0.076 \\
TSAT $(\%)$ & $28.62 \pm 16.71$ & $30.10 \pm 11.85$ & 0.72 \\
Ferritin $(\mathrm{ng} / \mathrm{mL})$ & $139.80 \pm 115.62$ & $162.00 \pm 97.24$ & 0.56 \\
Patients with low TSAT $(\leq 20 \%)$ and low ferritin $(\leq 100 \mathrm{ng} / \mathrm{mL})$ & 16.7 & 5.6 & 0.37 \\
$(\%)$ & & & \\
CRP $(\mathrm{mg} / \mathrm{dL})$ & $0.95 \pm 1.84$ & $1.48 \pm 4.14$ & 0.39 \\
eGFR $\left(\mathrm{mL} / \mathrm{min} / 1.73 \mathrm{~m}{ }^{2}\right)$ & $6.11 \pm 2.79$ & $5.67 \pm 2.36$ & 0.53 \\
ESA dosage $(\mu \mathrm{g} / 4$ weeks) & $92.87 \pm 63.29$ & $109.15 \pm 61.94$ & 0.23 \\
ERI $(\mu \mathrm{g} / \mathrm{kg} / \mathrm{g} / \mathrm{dL} / 4$ weeks $)$ & $0.171 \pm 0.130$ & $0.200 \pm 0.119$ & 0.38 \\
CTR $(\%)$ & $53.01 \pm 5.32$ & $53.66 \pm 6.66$ & 0.67 \\
Iron administration $(\%)$ & 32.4 & 11.5 & 0.07 \\
Patients with Hb $\geq 10 \mathrm{~g} / \mathrm{dL}(\%)$ & 48.6 & 19.2 & 0.02 \\
\hline
\end{tabular}

Values are given as mean \pm standard deviation for continuous variables and frequency (\%) for nominal variables $A l b$ albumin, $B U N$ blood urea nitrogen, $C E R A$ continuous erythropoietin receptor activator, $\mathrm{Cr}$ creatinine, $C R P$ C-reactive protein, $C T R$ cardiothoracic ratio, $D A$ darbepoetin- $\alpha, e G F R$ estimated glomerular filtration rate, ERI erythropoietin resistance index, $E S A$ erythropoiesis-stimulating agent, $H b$ hemoglobin, $M C V$ mean corpuscular volume, Ret reticulocyte, $R B C$ red blood cell, TSAT transferrin saturation 

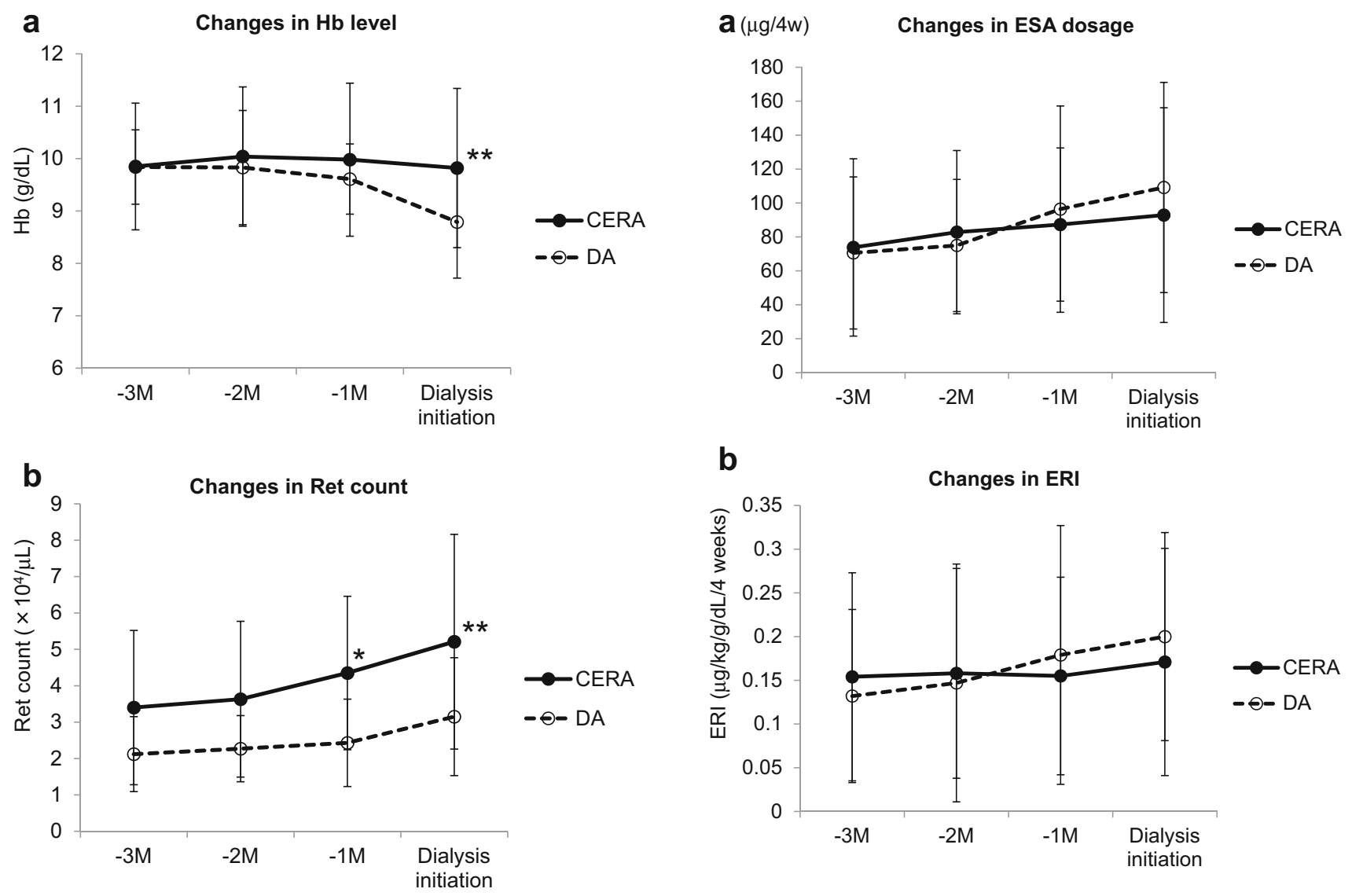

Fig. 2 a Changes in $\mathrm{Hb}$ level during 3 months before dialysis initiation; Hb level was significantly higher in the CERA group than in the DA group at dialysis initiation. b Changes in Ret count during 3 months before dialysis initiation; Ret count was significantly higher in the CERA group than in the DA group during 1 month before dialysis initiation. CERA continuous erythropoietin receptor activator, $D A$ darbepoetin- $\alpha, H b$ hemoglobin, Ret reticulocyte, $* P<0.05$ and $* * P<0.01$ vs. DA

of iron administration, tended to be higher in the CERA group than in the DA group during the 3 months before dialysis initiation in our study. However, no significant difference in TSAT, ferritin, or the extent of changes in TSAT and ferritin during the 3 months before dialysis initiation was found between the two groups. It has been reported previously that CERA is more effective than DA in suppressing hepcidin, which inhibits iron utilization [17]. Thus, these findings suggest that iron metabolism is more enhanced and there is more likely to be iron deficiency in the CERA group as a result of the increased efficiency of iron utilization caused by suppression of hepcidin due to CERA administration, although we did not examine the hepcidin levels.

Lastly, CERA, which is a PEGylated epoetin- $\beta$, may have the following inhibitory effects on drug degradation [18]: (1) affinity for epoetin receptors decreases, and its receptormediated intracellular degradation is inhibited; (2)

Fig. 3 a Changes in ESA dosage during 3 months before dialysis initiation; no significant difference was found between the two groups in the ESA dosage during 3 months before dialysis initiation. b Changes in ERI during 3 months before dialysis initiation; no significant difference was found between the two groups in the ERI during 3 months before dialysis initiation. CERA continuous erythropoietin receptor activator, $D A$ darbepoetin- $\alpha, E R I$ erythropoietin resistance index, ESA erythropoiesis-stimulating agent

degradation of sialic acid on the carbohydrate chain of epoetin- $\beta$ by serum sialidase is inhibited, and degradation by the liver is suppressed-in fact, the hematopoietic effect of CERA, but not rHuEPO, is preserved even when CERA is exposed to sialidase [19]; and (3) degradation of the protein moiety of epoetin- $\beta$ by serum proteolytic enzymes is inhibited. These are features not present in DA. As drug degradation is inhibited, this may have caused the effect of CERA to persist, and may have allowed for the erythropoietic effect to be maintained even at dialysis initiation; and this may have allowed the hemoglobin level to be maintained.

There are several limitations to this study. First, the conversion ratio between the dosage of CERA and that of DA has not yet been clearly determined, and they are also different in terms of receptor affinity and serum half-life; thus, a simple comparison between the two might be impossible. Therefore, the conversion ratio CER$\mathrm{A}: \mathrm{DA}=1: 1$ was used for the analysis conducted in this study, as in previous reports [12, 13]. During the 
Table 4 Extent of changes in clinical data during 3 months before dialysis initiation

\begin{tabular}{lccc}
\hline Extent of changes in data & CERA $(n=37)$ & DA $(n=26)$ & $P$ value \\
\hline Hb level $(\mathrm{g} / \mathrm{dL})$ & $-0.03 \pm 1.40$ & $-1.05 \pm 1.20$ & 0.006 \\
ESA dosage $(\mu \mathrm{g} / 4$ weeks) & $19.05 \pm 52.27$ & $38.58 \pm 66.71$ & 0.21 \\
ERI $(\mu \mathrm{g} / \mathrm{kg} / \mathrm{g} / \mathrm{dL} / 4$ weeks) & $0.020 \pm 0.076$ & $0.078 \pm 0.120$ & 0.045 \\
TSAT $(\%)$ & $-0.09 \pm 17.63$ & $-5.17 \pm 10.89$ & 0.71 \\
Ferritin $(\mathrm{ng} / \mathrm{mL})$ & $-25.52 \pm 78.77$ & $-28.16 \pm 65.10$ & 0.82 \\
eGFR $\left(\mathrm{mL} / \mathrm{min} / 1.73 \mathrm{~m}^{2}\right)$ & $-2.75 \pm 2.76$ & $-2.68 \pm 2.99$ & 0.71 \\
CTR $(\%)$ & $2.53 \pm 4.71$ & $3.45 \pm 2.71$ & 0.54 \\
\hline
\end{tabular}

Values are given as mean \pm standard deviation

$C E R A$ continuous erythropoietin receptor activator, CTR cardiothoracic ratio, DA darbepoetin- $\alpha, e G F R$ estimated glomerular filtration rate, ERI erythropoietin resistance index, ESA erythropoiesis-stimulating agent, $H b$ hemoglobin, TSAT transferrin saturation
3 months before dialysis initiation, no significant difference was found between the two groups in terms of ESA dosage. All of this suggests that the significant difference in hemoglobin levels at dialysis initiation did not necessarily mean that the dosage used in the CERA group was greater than that used in the DA group. Second, we did not examine differences in the hepcidin levels and the doses of iron administered between the CERA and DA groups. The percentage of iron administration tended to be lower in the DA group, which might influence the lower hemoglobin level at dialysis initiation in the DA group. We need to investigate the influence of hepcidin levels or the iron doses administered on the hemoglobin level in a prospective study in the future. Third, the patients in the DA group had a numerically higher creatinine level and lower eGFR. Since decreased kidney function is associated with increased uremic toxins and decreased endogenous erythropoietin, the hemoglobin level might be influenced by creatinine or eGFR. Thus, there may be a possible link between use of DA and an increased level of sickness, resulting in the DA group being more resistant to ESA than the CERA group. Fourth, the frequency of administration should be higher in the DA group in order to maintain the hemoglobin level since it is reported that the half-life of DA is shorter than that of CERA. It cannot be denied that the difference in the half-life between CERA and DA influenced our results. In our study, the administration interval for ESA was once every 4 weeks for most participants and there was no significant difference in the administration frequency between the CERA and DA group. Thus, we consider that our results reflect the reality of daily clinical practice as these patients usually go to hospital monthly in Japan. Fifth, it is possible that the ERI might not be a meaningful parameter in our study due to the frequency of administration. In addition, this is a very small sample size observational study. There are also differences between the two groups in terms of patient characteristics. A comparative study between the CERA and DA groups using a randomized controlled trial will need to be carried out in the future.

\section{Conclusions}

This study showed that the hemoglobin level and reticulocyte count were significantly higher in the CERA group than in the DA group at dialysis initiation. The findings of this study suggest that CERA may be more effective than DA in maintaining the hemoglobin level in patients with $\mathrm{CKD}$ in the 3 months before dialysis initiation.

\section{Compliance with Ethical Standards}

Conflict of interest Satoru Oka, Yoko Obata, Kenta Torigoe, Miki Torigoe, Shinichi Abe, Kumiko Muta, Yuki Ota, Mineaki Kitamura, Satoko Kawasaki, Misaki Hirose, Tadashi Uramatsu, Hiroshi Yamashita, Hideyuki Arai, Hiroshi Mukae, and Tomoya Nishino declare that they have no conflicts of interest.

Funding This study was not supported by any industry funding.

Ethical approval All procedures performed in studies involving human participants were in accordance with the ethical standards of the institutional and/or national research committee and with the 1964 Helsinki Declaration and its later amendments or comparable ethical standards. This study was approved by Nagasaki University Hospital's ethical review board (Approval Number 15122111). Formal consent is not required for this type of study.

Open Access This article is distributed under the terms of the Creative Commons Attribution-NonCommercial 4.0 International License (http://creativecommons.org/licenses/by-nc/4.0/), which permits any noncommercial use, distribution, and reproduction in any medium, provided you give appropriate credit to the original author(s) and the source, provide a link to the Creative Commons license, and indicate if changes were made. 


\section{References}

1. Vlagopoulos PT, Tighiouart H, Weiner DE, Griffith J, Pettitt D, Salem DN, et al. Anemia as a risk factor for cardiovascular disease and all-cause mortality in diabetes: the impact of chronic kidney disease. J Am Soc Nephrol. 2005;16:3403-10.

2. Kuriyama S, Tomonari H, Yoshida H, Hashimoto T, Kawaguchi Y, Sakai O. Reversal of anemia by erythropoietin therapy retards the progression of chronic renal failure, especially in nondiabetic patients. Nephron. 1997;77:176-85.

3. Kazory A, Ross EA. Anemia: the point of convergence or divergence for kidney disease and heart failure? J Am Coll Cardiol. 2009;53:639-47.

4. Silverberg DS, Wexler D, Iaina A, Schwartz D. The interaction between heart failure and other heart diseases, renal failure, and anemia. Semin Nephrol. 2006;26:296-306.

5. Leaf DE, Goldfarb DS. Interpretation and review of health-related quality of life data in CKD patients receiving treatment for anemia. Kidney Int. 2009;75:15-24.

6. Gouva C, Nikolopoulos P, Ioannidis JP, Siamopoulos KC. Treating anemia early in renal failure patients slows the decline of renal function: a randomized controlled trial. Kidney Int. 2004;66:753-60.

7. Portolés J, Torralbo A, Martin P, Rodrigo J, Herrero JA, Barrientos A. Cardiovascular effects of recombinant human erythropoietin in predialysis patients. Am J Kidney Dis. 1997;29:541-8.

8. Hayashi T, Suzuki A, Shoji T, Togawa M, Okada N, Tsubakihara Y, et al. Cardiovascular effect of normalizing the hematocrit level during erythropoietin therapy in predialysis patients with chronic renal failure. Am J Kidney Dis. 2000;35:250-6.

9. Levin A, Djurdjev O, Thompson C, Barrett B, Ethier J, Carlisle $\mathrm{E}$, et al. Canadian randomized trial of hemoglobin maintenance to prevent or delay left ventricular mass growth in patients with CKD. Am J Kidney Dis. 2005;46:799-811.

10. Macdougall IC, Eckardt KU. Novel strategies for stimulating erythropoiesis and potential new treatments for anaemia. Lancet. 2006;368:947-53.

11. Akizawa T, Saito A, Gejyo F, Suzuki M, Nishizawa Y, Tomino Y, et al. Co-JET Study Group. Impacts of recombinant human erythropoietin treatment during predialysis periods on the progression of chronic kidney disease in a large-scale cohort study (Co-JET study). Ther Apher Dial. 2014;18:140-8.

12. Koibuchi K, Miyagi M, Arai T, Aoki T, Aikawa A, Sakai K. Comparing the efficacy of continuous erythropoietin receptor activator and darbepoetin alfa treatments in Japanese patients with chronic kidney disease during the predialysis period: a propensity-matched analysis. Nephrology. 2015;20(Suppl 4):22-8.

13. Kawahara K, Minakuchi J, Yokota N, Suekane H, Tsuchida K, Kawashima S. Treatment of renal anaemia with erythropoiesisstimulating agents in predialysis chronic kidney disease patients: haemoglobin profile during the 6 months before initiation of dialysis. Nephrology. 2015;20(Suppl 4):29-32.

14. Tsubakihara Y, Nishi S, Akiba T, Hirakata H, Iseki K, Kubota M, et al. 2008 Japanese Society for Dialysis Therapy: guidelines for renal anemia in chronic kidney disease. Ther Apher Dial. 2010;14:240-75.

15. Levinsky H, Gafter U, Levi J, Allalouf D. Neuraminidase-like activity in sera of uremic anemic patients. Nephron. 1984;37:35-8.

16. Shannon JS, Lappin TR, Elder GE, Roberts GM, McGeown MG, Bridges JM. Increased plasma glycosidase and protease activity in uraemia: possible role in the aetiology of the anaemia of chronic renal failure. Clin Chim Acta. 1985;153:203-7.

17. Onuma S, Honda H, Kobayashi Y, Yamamoto T, Michihata T, Shibagaki K, et al. Effects of long-term erythropoiesis-stimulating agents on iron metabolism in patients on hemodialysis. Ther Apher Dial. 2015;19:582-9.

18. Naruse T, Kukita K, Miyazaki S, Suzuki H, Shigematsu T, Hayakawa $\mathrm{H}$, et al. Pharmacokinetic properties of C.E.R.A. (continuous erythropoietin receptor activator) in Japanese chronic kidney disease patients not on dialysis [in Japanese]. Jpn Pharmacol Ther. 2010;38:1159-74.

19. Aizawa K, Kawasaki R, Tashiro Y, Hirata M, Endo K, Shimonaka Y. Epoetin beta pegol, but not recombinant erythropoietin, retains its hematopoietic effect in vivo in the presence of the sialic acid-metabolizing enzyme sialidase. Int $\mathrm{J}$ Hematol. 2016;104:182-9. 